\title{
The Association of Polymorphisms in Nrf2 and Genes Involved in Redox Homeostasis in the Development and Progression of Clear Cell Renal Cell Carcinoma
}

\author{
Smiljana Mihailovic $\left(\mathbb{D},{ }^{1}\right.$ Vesna Coric $\left(\mathbb{D},{ }^{2,3}\right.$ Tanja Radic $\left(\mathbb{D},{ }^{4}\right.$ Ana Savic Radojevic $\mathbb{D}^{2},{ }^{2,3}$ \\ Marija Matic $\mathbb{D}^{2,3}$ Dejan Dragicevic $\left(\mathbb{D},{ }^{3,5}\right.$ Milica Djokic $\left(\mathbb{D},{ }^{6}\right.$ Vladimir Vasic $\left(\mathbb{D},{ }^{7}\right.$ \\ Zoran Dzamic $\mathbb{D},{ }^{3,5}$ Tatjana Simic $\mathbb{D}^{2,3,8}$ Jovan Hadzi-Djokic $\mathbb{D}^{8}{ }^{8}$ \\ and Marija Pljesa Ercegovac $\mathbb{D i D}^{2,3}$
}

${ }^{1}$ The Obstetrics and Gynaecology Clinic Narodni Front, 11000, Serbia

${ }^{2}$ Institute of Medical and Clinical Biochemistry, 11000, Serbia

${ }^{3}$ Faculty of Medicine, University of Belgrade, 11000, Serbia

${ }^{4}$ Institute of Mental Health Belgrade, 11000, Serbia

${ }^{5}$ Clinic of Urology, Clinical Center of Serbia, 11000, Serbia

${ }^{6}$ Institute for Oncology and Radiology of Serbia, 11000, Serbia

${ }^{7}$ Department of Urology, University Medical Center Zvezdara, 11000, Serbia

${ }^{8}$ Serbian Academy of Sciences and Arts, 11000, Serbia

Correspondence should be addressed to Marija Pljesa Ercegovac; m.pljesa.ercegovac@gmail.com

Received 23 October 2020; Revised 28 November 2020; Accepted 3 April 2021; Published 17 April 2021

Academic Editor: Aldrin V. Gomes

Copyright (c) 2021 Smiljana Mihailovic et al. This is an open access article distributed under the Creative Commons Attribution License, which permits unrestricted use, distribution, and reproduction in any medium, provided the original work is properly cited.

\begin{abstract}
Deleterious effects of SNPs found in genes encoding transcriptional factors, as well as antioxidant and detoxification enzymes, are disputable; however, their functional significance seems to modify the risk for clear cell renal cell carcinoma (ccRCC) development and progression. We investigated the effect of specific Nrf2, SOD2, GPX1 gene variants and GSTP1ABCD haplotype on ccRCC risk and prognosis and evaluated the association between GSTP1 and regulatory (JNK1/2) and executor (caspase-3) apoptotic molecule expression in ccRCC tissue samples and the presence of GSTP1 : JNK1/2 protein : protein interactions. Genotyping was performed in $223 \mathrm{ccRCC}$ patients and 336 matched controls by PCR-CTTP and qPCR. Protein expression was analyzed using immunoblot, while the existence of GSTP1:JNK1 protein:protein interactions was investigated by immunoprecipitation experiments. An increased risk of ccRCC development was found among carriers of variant genotypes of both SOD2 rs4880 and GSTP1 rs1695 polymorphisms. Nrf2 rs6721961 genetic polymorphism in combination with both rs4880 and rs1695 showed higher ccRCC risk as well. Haplotype analysis revealed significant risk of ccRCC development in carriers of the GSTP1C haplotype. Furthermore, GSTP1 variant forms seem to affect the overall survival in ccRCC patients, and the proposed molecular mechanism underlying the GSTP1 prognostic role might be the presence of GSTP1 : JNK1/2 protein : protein interactions.
\end{abstract}

\section{Introduction}

Cellular redox homeostasis is maintained by constant metabolic fluxes and redox feedback consisting of electrophilic molecules produced by all kinds of stressors that activate diverse mechanisms aimed at reestablishing nucleophilic environment [1]. Disturbance of this fine balance between reactive oxygen species (ROS) production and their disintegration leads to oxidative stress and cellular damage on multiple levels [2]. In order to adapt, a phenotypic switch has to take place [1]. Cells that have a high proliferation rate, such as cancer cells, demand constant energy production to maintain biosynthesis of macromolecules. In order to adapt and support their basic needs, both intrinsic and extrinsic 
molecular mechanisms are involved in modifying cellular metabolism [3]. While constantly rapidly proliferating, cancer cells are, at the same time, exposed to increased ROS levels, which further upregulate antioxidant systems and create environment in which they are able to develop new redox balance and resistance to oxidative damage [3].

Clear cell renal cell carcinoma (ccRCC) remains one of the most frequent and the most aggressive adult renal malignancies, accounting for up to $90 \%$ of all kidney tumors $[4,5]$. Since alterations in metabolism are among ccRCC hallmarks, it has been suggested that besides histological classification of RCC, certain molecular subtypes should also be identified $[6,7]$. Precise classification is of utmost importance, since it might reveal types with more or less aggressive clinical features and therefore point out which patients should be more closely monitored and followed [8].

Clear cell RCC belongs to types of carcinomas associated with Keap1/Nrf2 (Kelch-like ECH-associated protein 1/nuclear factor (erythroid-derived 2)-like2) pathway alterations [8]. Namely, when cellular levels of reactive oxygen species and electrophiles are increased, specific adaptive cytoprotective response is activated, including changes in the Keap1/Nrf2 pathway $[9,10]$. Induced allosteric changes in Keap1 lead to decreased proteasomal degradation of the transcriptional factor Nrf2 [10]. Once accumulated, Nrf2 enters the cell nucleus and binds to antioxidant response element (ARE) DNA sequences of Nrf2 target genes, further causing intensified transcription of numerous enzymes, including detoxifying enzymes, metabolic enzymes, and stress response proteins $[8,10,11]$. Although at first perceived as an anticancer molecule, some authors emphasize the role of Nrf2 in cancer cell survival and even suggest that it should be regarded as a possible target for future anticancer therapeutic approaches $[9,12,13]$.

Among various enzymes encoded by Nrf2 target genes and regulated by their binding to AREs are glutathione S-transferases (GST). They represent a family of multifunctional enzymes involved in a number of catalytic and noncatalytic processes, still traditionally recognized as phase II cellular detoxification system enzymes [3, 14]. The liver, lung, and kidneys, as organs with intense metabolic activity, are known to have high expression of cytosolic GSTs, especially the pi (GSTP) form, whose gene activation is regulated by Nrf2 $[14,15]$. GSTP1 also possesses binding activity toward macromolecules, as well as small molecules, and displays ability to participate in a large signal transduction pathway $[14,16]$. Specifically, GSTP1 acts as a negative regulator of kinasedependent apoptotic signaling pathways by forming protein :protein complexes with regulatory mitogen-activated kinases such as JNK1 (c-Jun NH2-terminal kinase) [14, 17]. The particular GSTP1:JNK1 interaction has gained attention as the new, functional link between the upregulated GSTP1 and malignant phenotype [3]. Additionally, GSTP1 has a potential to form a GSTP1/Nrf2 protein complex, suggesting a possibility that GSTP1 protein might help Nrf2 stabilization and its further actions [18]. When considering its role in cancer metabolism, in addition to detoxification of potential cancerogenic substances, GSTP1 is capable of increasing drug efflux from the cell thus contributing to chemoresistance [19].
Since cancer cells are energy-dependent, metabolic reprogramming is the basis of their sustenance [7]. In order to keep up with high energy demands and to defend themselves from many reactive molecules, tumor cells rely on enzymes that enable both processes $[20,21]$. There are three isoenzymes of SOD, a major antioxidant enzyme [22]. In the reaction catalyzed by mitochondrial $\mathrm{SOD} 2, \mathrm{H}_{2} \mathrm{O}_{2}$, a wellknown molecule with novel functions in cell proliferation, differentiation, and migration, is being produced. In addition to acting as a signaling molecule, $\mathrm{H}_{2} \mathrm{O}_{2}$ facilitates activation of AMP-activated kinase and promotes glycolysis which is a key change for cancer cells $[20,22]$. Therefore, by controlling the $\mathrm{H}_{2} \mathrm{O}_{2}$ production, SOD2 plays an important role in numerous pathways.

And while SOD2 leads to $\mathrm{H}_{2} \mathrm{O}_{2}$ synthesis, another key antioxidant enzyme, glutathione peroxidase (GPX), leads to its further reduction and production of a neutral water molecule [23]. Eight members comprise the GPX family [24]. By helping cancer cells eliminate potentially harmful hydrogen peroxide, the role of GPX1 as the most abundant GPX form might be contradictory [25]. Namely, its increased activity protects normal cells from oxidative damage, while this could be helpful for cancer cells to escape ROS as well [25].

Both the Nrf2 gene and genes encoding GSTP1, SOD2, and GPX1 have functional polymorphisms, which either change the level of expression of specific protein or affect the activity of synthesized proteins. The widely analyzed Nrf2 SNP polymorphism rs6721961 involves substitution of $\mathrm{C}$ to A, positioned at -617 of the proximal promoter [26]. Definite consequent functional changes are still unsolved, and it is discussed whether higher or lower transcriptional activity is associated with a variant-type genotype (-617AA) [27]. However, since this SNP is located in the ARE-like motif of the gene, importance for self-induction of the Nrf2 is being emphasized throughout the literature [26, 28, 29]. In the case of GSTP1 gene polymorphisms, two most commonly occurring SNPs are rs1695 and rs1138272 [30]. Substitution of A313G in the case of rs1695 causes change of isoleucine with valine at position 105 (Ile105Val) [31]. This Val allele variant represents a more potent c-Jun $\mathrm{N}$-terminal kinase 1 (JNK1) inhibitor and has a stronger antiapoptotic effect [32]. The presence of $\mathrm{T}$ instead of $\mathrm{C}$ at position 341 results in coding of protein with valine instead of alanine (rs1138272, Ala114Val) [33]. It is assumed that the $341 \mathrm{~T}$ variant of GSTP might have decreased activity or modified substrate specificity [34]. The haplotype GSTP1ABCD represents a combination of these two polymorphisms. When it comes to SOD2 polymorphism, rs4880 corresponds to substitution of $\mathrm{C}>\mathrm{T}$ in exon 2 leading to change from alanine to valine at position 16 [35]. Since there is a channel within the inner mitochondrial membrane that cannot import the Val16 variant of SOD2 as efficiently as Ala16, the Val16 variant remains trapped and later degraded by the proteasome [35]. The mostly studied SNP in the case of the GPX1 gene is rs1050450 (Pro200Leu). Due to change of proline with leucine, secondary and tertiary structures of GPX1 are altered, leading to conformational change of the enzyme as a whole [36]. Proline is basically essential, because of its unsubstituted amino group on the $\alpha$ carbon atom which 
enables formation of a specific kink; therefore, when absent, the whole structure is modified [36].

Considering the potential functional significance of polymorphisms in genes encoding the Nrf2 transcriptional factor, as well as antioxidant SOD2, GPX1, and detoxification GSTP1 enzymes in both the onset and prognosis of clear cell RCC, the aim of this study was to evaluate the effect of specific Nrf2, SOD2, and GPX1 gene variants and GSTP1ABCD haplotype on the risk, development, and postoperative prognosis in patients with ccRCC. Furthermore, the aim was to evaluate the association between GSTP1 expression and expression of regulatory (JNK1/2) and executor (caspase-3) apoptotic molecules in human ccRCC tissue samples, as well as the presence of GSTP1:JNK1/2 protein:protein interactions.

\section{Materials and Methods}

2.1. Participants. The case-control study included 223 patients with histologically confirmed clear cell renal cell carcinoma treated and followed at the Clinic of Urology of Clinical Center of Serbia, Belgrade. Incident cases were recruited at the time of diagnosis which included the presence of malignantly enhanced lesions detected by imaging techniques and confirmed by histological diagnosis. Obtained blood and tissue samples were assessed within the Biobank formed in the Laboratory for Functional Genetics and Proteomics at the Institute of Medical and Clinical Biochemistry of the Faculty of Medicine, University of Belgrade. The enrolled 336 controls were gender- and age-matched cancerfree subjects. These individuals with no previous history of cancer had undergone surgery for benign conditions at the same clinical center, unrelated to both nonmalignant and malignant urological conditions. Participants gave their informed consent for inclusion in the study. The study was conducted in accordance with the Declaration of Helsinki, and the protocol was approved by the Ethics Committee of the Faculty of Medicine, University of Belgrade (no. 29/X-3). Both cases and controls were interviewed using a standard epidemiological questionnaire in order to gain information about risk factors for ccRCC development. Smokers were defined as subjects who had a period of at least 60 days of consuming cigarettes prior to inclusion in the study. Pack-years was calculated by the formula pack-years = (cigarettes/day $\div 20) \times$ years of smoking. Overall survival was defined as time from nephrectomy to the date of death or last follow-up (November 2018).

2.2. DNA Isolation. Genomic DNA was isolated from $200 \mu \mathrm{l}$ of the whole blood sample or from $25 \mathrm{mg}$ of distant nontumor kidney tissue samples, using a QIAamp DNA mini kit (Qiagen, Chatsworth, CA, USA). Isolated DNA was stored at $-20^{\circ} \mathrm{C}$. The concentration, as well as purity of isolated DNA, was measured by spectrophotometry at 230, 260, 280, and $320 \mathrm{~nm}$ on GeneQuant pro (Biochrom, Cambridge, England).

2.3. Analysis of Examined Genotypes. The polymorphism rs6721961 for Nrf2 was examined by the PCR-CTTP (poly- merase chain reaction with confronting two-pair primers) method according to Shimoyama et al. [37]. Products of amplification were divided by electrophoresis with $2 \%$ agarose gel. Visualization of PCR products was enabled with SYBR $^{\circledR}$ Safe DNA Gel Stain (Invitrogen Corporation, Carlsbad, California, USA) on a UV ChemiDoc camera (BioRad, Hercules, California, USA). A lane containing 282 and 113 bp was considered a C/C genotype; a lane with 282 , 205 , and $113 \mathrm{bp}$, a heterozygous genotype; and a lane with 282 and $205 \mathrm{bp}$, a A/A genotype.

Genotyping of GSTP1 (rs1695 and rs1138272), SOD2 (rs4880), and GPX1 (rs1050450) was done by applying quantitative polymerase chain reaction (qPCR) on Mastercycler ep realplex (Eppendorf, Hamburg, Germany) using appropriate assays of Applied Biosystems TaqMan Drug Metabolism Genotyping (Life Technologies, Applied Biosystems, Carlsbad, CA, USA). Assays C_3237198_20 in the case of GSTP1 rs1695, C_1049615_20 for GSTP1 rs 1138272 , and C_8709053_10 were used for SOD2. For the GPX1 rs 1050450 polymorphism, a custom-designed assay with sequences $5^{\prime}$ VIC-ACAGCT GGGCCCTT-MGB- $3^{\prime}$ and $5^{\prime}$ FAM-ACAGCTGAGCCCTTMGB-3' was used.

2.4. Immunoblot Analysis. Cytosols were obtained from ccRCC tumor $(n=20)$ and respective nontumor kidney tissue samples. A pool of nontumor kidney tissue was made by mixing the equal parts of six different samples. $50 \mu \mathrm{g}$ of total protein per sample was subjected to immunoblot analysis of JNK1/2, GSTP1, and cleaved caspase-3 expression $[38,39]$. Membranes were blocked overnight and treated with primary antibodies against JNK1/2 (Sigma-Aldrich, St. Louis, Missouri, USA), GSTP1 (Abcam, Cambridge, UK), cleaved caspase-3 (Cell Signaling, Danvers, Massachusetts, USA), and housekeeping protein $\beta$-actin (Sigma-Aldrich, St. Louis, Missouri, USA). Afterwards, membranes were incubated with appropriate secondary antibodies, treated with a chemiluminescence detection substrate (Invitrogen Corporation, Carlsbad, CA, USA), and exposed to X-ray films (Amersham Hyperfilm ECL, GE Healthcare, Buckinghamshire, England). Densitometry analysis was performed using ImageJ (National Institutes of Health, Bethesda, USA). In order to obtain relative quantitation, the results were normalized using $\beta$-actin housekeeping protein.

In order to investigate the presence of GSTP1:JNK1 protein : protein interactions in tumor ccRCC samples, immunoprecipitation experiments were performed using Catch and Release $^{\circledR}$ v2.0 High Throughput (HT) Immunoprecipitation Assay Kit-96 well (Upstate Biotech Inc. for Merck Millipore, Darmstadt, Germany) according to the manufacturer's instructions. Namely, a 96-well filter plate was used for a precoating procedure with provided $20 \% w / v$ slurry resign and Affinity Ligand. Selected cytosols, containing $1 \mu \mathrm{g} / \mu \mathrm{l}$ of total cell proteins, previously quantified by using the Bicinchoninic Acid Protein Assay Kit (BCA-1, Sigma-Aldrich, St. Louis, Missouri, USA) were incubated with $2 \mu \mathrm{g}$ of the primary antibody against GSTP1 (Cell Signaling, Danvers, Massachusetts, USA), followed by several washing steps. Finally, samples were resuspended in $30 \mu \mathrm{l}$ of $2 \mathrm{x}$ Laemmli buffer (Bio-Rad, Hercules, CA, USA), denatured at $90^{\circ} \mathrm{C}$ for five minutes, 
TABLE 1: Baseline characteristics of ccRCC patients and age- and gender-matched controls.

\begin{tabular}{|c|c|c|c|c|}
\hline & ccRCC patients & Controls & OR $\left(95 \% \mathrm{CI}^{\mathrm{a}}\right)$ & $p$ \\
\hline Age (years) ${ }^{b}$ & $58.95 \pm 11.65$ & $60.44 \pm 10.84$ & I & 0.125 \\
\hline \multicolumn{5}{|l|}{ Gender, $n(\%)$} \\
\hline Female & $73(33)$ & $138(41)$ & $1.00^{\mathrm{c}}$ & \\
\hline Male & $147(67)$ & $198(59)$ & $1.467(0.756-2.847)^{\mathrm{d}}$ & 0.258 \\
\hline \multicolumn{5}{|l|}{ Obesity, $n(\%)^{\mathrm{e}}$} \\
\hline $\mathrm{BMI}<25$ & $65(36)$ & $110(35)$ & $1.00^{\mathrm{C}}$ & \\
\hline $\mathrm{BMI}>25$ & $115(64)$ & $204(65)$ & $0.866(0.494-1.518)^{\mathrm{f}}$ & 0.616 \\
\hline BMI $\left(\mathrm{kg} / \mathrm{m}^{2}\right)$ & $26.61 \pm 4.43$ & $26.78 \pm 4.08$ & l & 0.677 \\
\hline \multicolumn{5}{|l|}{ Smoking, $n(\%)^{\mathrm{e}}$} \\
\hline Never & $82(44)$ & $164(49)$ & $1.00^{\mathrm{C}}$ & \\
\hline Ever ${ }^{\mathrm{g}}$ & $106(56)$ & $171(51)$ & $1.289(0.863-1.925)^{\mathrm{h}}$ & 0.215 \\
\hline Pack-years ${ }^{\mathrm{i}}$ & $31(0.30-96.00)$ & $30.00(0.20-88.00)$ & 1 & 0.131 \\
\hline \multicolumn{5}{|c|}{ Hypertension, $n(\%)^{\mathrm{e}}$} \\
\hline No & $83(45)$ & $211(65)$ & $1.00^{\mathrm{c}}$ & \\
\hline Yes & $102(55)$ & $116(35)$ & $2.450(1.375-4.435)^{j}$ & 0.002 \\
\hline \multicolumn{5}{|c|}{ Tumor grade, $n(\%)^{\mathrm{k}}$} \\
\hline Grade I, G1 & $28(15)$ & & & \\
\hline Grade II, G2 & $106(55)$ & & & \\
\hline Grade III, G3 & $49(26)$ & & & \\
\hline Grade IV, G4 & $8(4)$ & & & \\
\hline \multicolumn{5}{|l|}{ pT stage, $n(\%)^{\mathrm{k}}$} \\
\hline pT1 & $93(45)$ & & & \\
\hline pT2 & $23(11)$ & & & \\
\hline pT3 & $87(42)$ & & & \\
\hline pT4 & $5(2)$ & & & \\
\hline
\end{tabular}

${ }^{\mathrm{a}} \mathrm{CI}$ : confidence interval; ${ }^{\mathrm{b}}$ mean $\pm \mathrm{SD} ;{ }^{\mathrm{c}}$ reference group; ${ }^{\mathrm{d}}$ OR: odds ratio adjusted for age, BMI (body mass index), pack-years, and hypertension; ${ }^{\mathrm{e}}$ based on the data available; ${ }^{\mathrm{f}} \mathrm{OR}$ adjusted for age, gender, pack-years, and hypertension; ${ }^{\mathrm{g}}$ minimum of a 60 -day period any time prior to the study onset; ${ }^{\mathrm{h}} \mathrm{OR}$ adjusted for age, gender, BMI, and hypertension; ${ }^{\mathrm{i}}$ median (Min-Max); ${ }^{\mathrm{j}} \mathrm{OR}$ adjusted for age, gender, BMI, and pack-years; ${ }^{\mathrm{k}}$ data available on patients' tumor grade and $\mathrm{pT}$ stage, depending on the type of surgery and pathohistological diagnostics.

and collected by centrifugation at $1500 \mathrm{rpm}$ for one minute. Supernatant fraction was further subjected to SDS-PAGE and Western blot analysis according to the previously described protocols.

2.5. Statistical Analysis. Calculations for this investigation were performed using the SPSS software version 17.0 (Chicago, IL, USA). Continuous variables were expressed as mean \pm standard deviation $(\mathrm{SD})$ or median (minimummaximum). Frequency ( $n, \%)$ counts were used for categorical variables. Distribution of different variables was tested by using the Kolmogorov-Smirnov test. For each examined polymorphism, the Hardy-Weinberg equilibrium was tested. The risk each genetic variant carries for ccRCC development was computed by odds ratios (OR) and 95\% confidence intervals (CI) by logistic regression analysis. OR was adjusted for age, gender, and variables indicating recognized risk factors for ccRCC as potential confounders. Survival analysis was performed using the Kaplan-Meier method to estimate the cumulative survival probability. The log-rank test was performed for the assessment of differences in survival according to the different categories of variables. The associ- ation between GSTP1 and cleaved caspase-3 expression was analyzed using Spearman's coefficient of linear correlation.

\section{Results and Discussion}

3.1. Analysis of Genotypes. The analyzed sample included a total number of 223 ccRCC patients and 336 age- and gender-matched controls with the same geographic origin. The main demographic and clinical features of patients and controls are summarized in Table 1.

As presented, recognized risk factors for ccRCC, history of obesity, hypertension, and smoking status, were evaluated. While no significant difference among groups was found regarding obesity and smoking status, more than $50 \%$ of patients were presenting hypertension in comparison with $35 \%$ hypertensive controls. Additionally, subjects who had history of hypertension exhibited 2.45-fold increased risk for ccRCC development compared to normotensive subjects $(95 \% \mathrm{CI}=1.375-4.435, p<0.05)$. Grade II, according to the Fuhrman grading system, was the most prevalent among enrolled cases (106 patients-55\%). When staged according 
TABLE 2: Nrf2, SOD2, GPX1, and GSTP1 genotypes in relation to the risk of ccRCC.

\begin{tabular}{|c|c|c|c|c|}
\hline Genotypes & ccRCC patients, $n(\%)$ & Controls, $n(\%)$ & OR $(95 \% \mathrm{CI})^{\mathrm{a}}$ & $p$ \\
\hline \multicolumn{5}{|l|}{$N r f 2($ rs6721961) } \\
\hline $\mathrm{C} / \mathrm{C}^{\mathrm{c}}$ & $166(77)$ & $241(72)$ & $1.00^{\mathrm{b}}$ & \\
\hline $\mathrm{C} / \mathrm{A}$ and $\mathrm{A} / \mathrm{A}^{\mathrm{d}}$ & $50(23)$ & $95(28)$ & $0.692(0.370-1.295)$ & 0.250 \\
\hline \multicolumn{5}{|l|}{ SOD2 (rs4880) } \\
\hline $\mathrm{Ala} / \mathrm{Ala}^{\mathrm{e}}$ & $45(30)$ & $111(21)$ & $1.00^{\mathrm{b}}$ & \\
\hline $\mathrm{Ala} / \mathrm{Val}$ and $\mathrm{Val} / \mathrm{Val}^{\mathrm{f}}$ & $175(70)$ & $225(79)$ & $4.521(2.167-9.432)$ & $<0.001$ \\
\hline \multicolumn{5}{|l|}{ GPX1 (rs1050450) } \\
\hline Pro/Pro ${ }^{\mathrm{g}}$ & $109(49)$ & $142(42)$ & $1.00^{\mathrm{b}}$ & \\
\hline Pro/Leu and Leu/Leu ${ }^{\mathrm{h}}$ & $113(51)$ & $194(58)$ & $0.567(0.323-0.994)$ & 0.048 \\
\hline \multicolumn{5}{|l|}{ GSTP1 (rs1695) } \\
\hline Ile/Ile $e^{i}$ & $55(25)$ & $159(47)$ & $1.00^{\mathrm{b}}$ & \\
\hline $\mathrm{Ile} / \mathrm{Val}+\mathrm{Val} / \mathrm{Val}^{\mathrm{j}}$ & $168(75)$ & $177(53)$ & $3.714(1.952-7.069)$ & $<0.001$ \\
\hline \multicolumn{5}{|l|}{ GSTP1 (rs1138272) } \\
\hline Ala/Ala ${ }^{\mathrm{k}}$ & $197(89)$ & $297(89)$ & $1.00^{\mathrm{b}}$ & \\
\hline $\mathrm{Ala} / \mathrm{Val}+\mathrm{Val} / \mathrm{Val}^{1}$ & $25(11)$ & $39(11)$ & $0.712(0.309-1.642)$ & 0.426 \\
\hline \multicolumn{5}{|l|}{ GSTP1 (rs1695 and rs1138272) } \\
\hline$\left(\right.$ Ile/Ile) $(\text { Ala/Ala })^{\mathrm{m}}$ & $54(24)$ & $144(43)$ & $1.00^{\mathrm{b}}$ & \\
\hline$(\mathrm{Ile} / \mathrm{Ile})(\mathrm{Ala} / \mathrm{Val}+\mathrm{Val} / \mathrm{Val})^{\mathrm{n}}$ & $1(1)$ & $15(4)$ & $0.000\left(\mathrm{NA}^{\mathrm{q}}\right)$ & 0.999 \\
\hline$(\mathrm{Ile} / \mathrm{Val}+\mathrm{Val} / \mathrm{Val})(\mathrm{Ala} / \mathrm{Ala})^{\mathrm{o}}$ & $143(64)$ & $153(46)$ & $3.250(1.668-6.331)$ & 0.001 \\
\hline$(\mathrm{Ile} / \mathrm{Val}+\mathrm{Val} / \mathrm{Val})(\mathrm{Ala} / \mathrm{Val}+\mathrm{Val} / \mathrm{Val})^{\mathrm{p}}$ & $24(11)$ & $24(7)$ & $2.719(0.970-7.624)$ & 0.057 \\
\hline
\end{tabular}

${ }^{\mathrm{a} O R}$ : odds ratio adjusted for age, gender, BMI, pack-years, and hypertension; CI: confidence interval; ${ }^{\mathrm{b}}$ reference group; ${ }^{\mathrm{c}} \mathrm{C} / \mathrm{C}$ : carriers of both referent alleles; ${ }^{\mathrm{d}} \mathrm{C} / \mathrm{A}$ and $\mathrm{A} / \mathrm{A}$ : carriers of at least one variant allele; ${ }^{\mathrm{e}} \mathrm{Ala} / \mathrm{Ala}$ : carriers of both referent alleles; ${ }^{\mathrm{f}} \mathrm{Ala} / \mathrm{Val}$ and Val/Val: carriers of at least one variant allele; ${ }^{\mathrm{g}}$ Pro/Pro: carriers of both referent alleles; ${ }^{\mathrm{h}} \mathrm{Pro} / \mathrm{Leu}$ and Leu/Leu: carriers of at least one variant allele; ${ }^{\mathrm{i}} \mathrm{Ile} / \mathrm{Il}$ : carriers of both referent alleles; ${ }^{\mathrm{j}} \mathrm{Ile} / \mathrm{Val}$ and Val/Val: carriers of at least one variant allele; ${ }^{\mathrm{k}} \mathrm{Ala} / \mathrm{Ala}$ : carriers of both referent alleles; ${ }^{\mathrm{l}} \mathrm{Ala} / \mathrm{Val}$ and $\mathrm{Val} / \mathrm{Val}$ : carriers of at least one variant allele; ${ }^{\mathrm{m}}$ (Ile/Ile) (Ala/Ala): carriers of both referent alleles for rs1695 and rs1138272; ${ }^{\mathrm{n}}$ (Ile/Ile) (Ala/Val+Val/Val): carriers of both referent alleles for rs1695 and at least one variant allele rs1138272; ${ }^{\circ}(\mathrm{Ile} / \mathrm{Val}+\mathrm{Val} / \mathrm{Val})$ (Ala/Ala): carriers of at least one variant allele for $\mathrm{rs} 1695$ and both referent alleles for rs1138272; ${ }^{\mathrm{P}}(\mathrm{Ile} / \mathrm{Val}+\mathrm{Val} / \mathrm{Val})(\mathrm{Ala} / \mathrm{Val}+\mathrm{Val} / \mathrm{Val})$ : carriers of at least one variant allele for both rs1695 and rs1138272; ${ }^{9} \mathrm{NA}$ : not applicable.

to the TNM system, we found pT1 and pT3 to be the most numerous stages (93 pT1 cases and 87 pT3 cases).

The distribution of specific genotypes among ccRCC patients and controls is shown in Table 2.

No significant ccRCC risk was revealed for subjects carrying the C/A and A/A Nrf2 genotype in comparison with carriers of the $\mathrm{C} / \mathrm{C}$ genotype $(\mathrm{OR}=0.692,95 \% \mathrm{CI}=0.370-1.295$, $p=0.250)$. On the contrary, the risk for ccRCC development was highly increased in individuals with at least one SOD2 Val allele or precisely Ala/Val and Val/Val SOD2 genotypes $(\mathrm{OR}=4.521,95 \% \mathrm{CI}=2.167-9.432, p<0.001)$. Regarding GPX1 polymorphism, the risk for ccRCC development was reduced in subjects carrying Pro/Leu and Leu/Leu genotypes when compared to individuals with the Pro/Pro genotype $(\mathrm{OR}=0.567,95 \% \mathrm{CI}=0.323-0.994, p=0.048)$. GSTP1 polymorphisms rs1695 and rs1138272 were studied individually and in combination, as well as the GSTP1ABCD haplotype. As presented, subjects with the Ile/Val and Val/Val rs1695 genotype combined with the Ala/Ala rs1138272 genotype had more than 3-fold increased risk for developing clear cell renal cell carcinoma in comparison with carriers of referent genotypes for both polymorphisms $(\mathrm{OR}=3.250,95 \% \mathrm{CI}=$ $1.668-6.331, p=0.001)$.

As a part of an immensely complex redox homeostasis maintenance system, the examined enzymes and their genetic polymorphisms were assessed in combination (Table 3).
When observed altogether, subjects with the C/C Nrf2 genotype who were, at the same time, carrying the Ala/Val or $\mathrm{Val} / \mathrm{Val}$ SOD2 genotype, exhibited three-fold increased ccRCC risk (OR 3.234, 95\% CI $=1.436-7.280, p=0.005$ ), while subjects with C/A or A/A Nrf2 in combination with the Ala/Val or $\mathrm{Val} / \mathrm{Val}$ SOD2 genotype had 2.9-fold increased risk for ccRCC development $(\mathrm{OR}=2.918,95 \% \mathrm{CI}=1.131-7.532$, $p=0.027)$. Almost equally higher risk was found among carriers of combined $\mathrm{C} / \mathrm{C} \mathrm{Nrf2}$ and Ile/Val or $\mathrm{Val} / \mathrm{Val}$ GSTP1 rs1695 genotypes $(\mathrm{OR}=3.211$, 95\% CI 1.516$6.814, p=0.002)$. Logistic regression showed no substantial risk when Nrf2 genotypes were analyzed in combination with GPX1 and GSTP1 rs1138272 genotypes.

The increased ccRCC risk was the most pronounced when SOD2 and either GSTP1 rs1695 or rs1138272 polymorphisms were examined. Ala/Val and $\mathrm{Val} / \mathrm{Val}$ SOD2 genotypes in combination with Ile/Val and Val/Val rs1695 genotypes were associated with almost 20-fold increased risk $(\mathrm{OR}=19.724,95 \% \mathrm{CI}=4.267-91.165, p<0.001)$, while 4-fold increased risk for ccRCC development was observed when in combination with the Ala/Ala GSTP1 rs1138272 genotype $(\mathrm{OR}=4.374,95 \% \mathrm{CI}=2.012-9.508, p<0.001)$. Finally, the presence of the GPX1 Pro/Pro genotype combined with either the Ala/Val or $\mathrm{Val} / \mathrm{Val}$ SOD2 genotype and Ile/Val or Val/Val GSTP1 rs1695 genotype leads to significantly higher risk for this cancer $(\mathrm{OR}=3.653,95 \%$ 


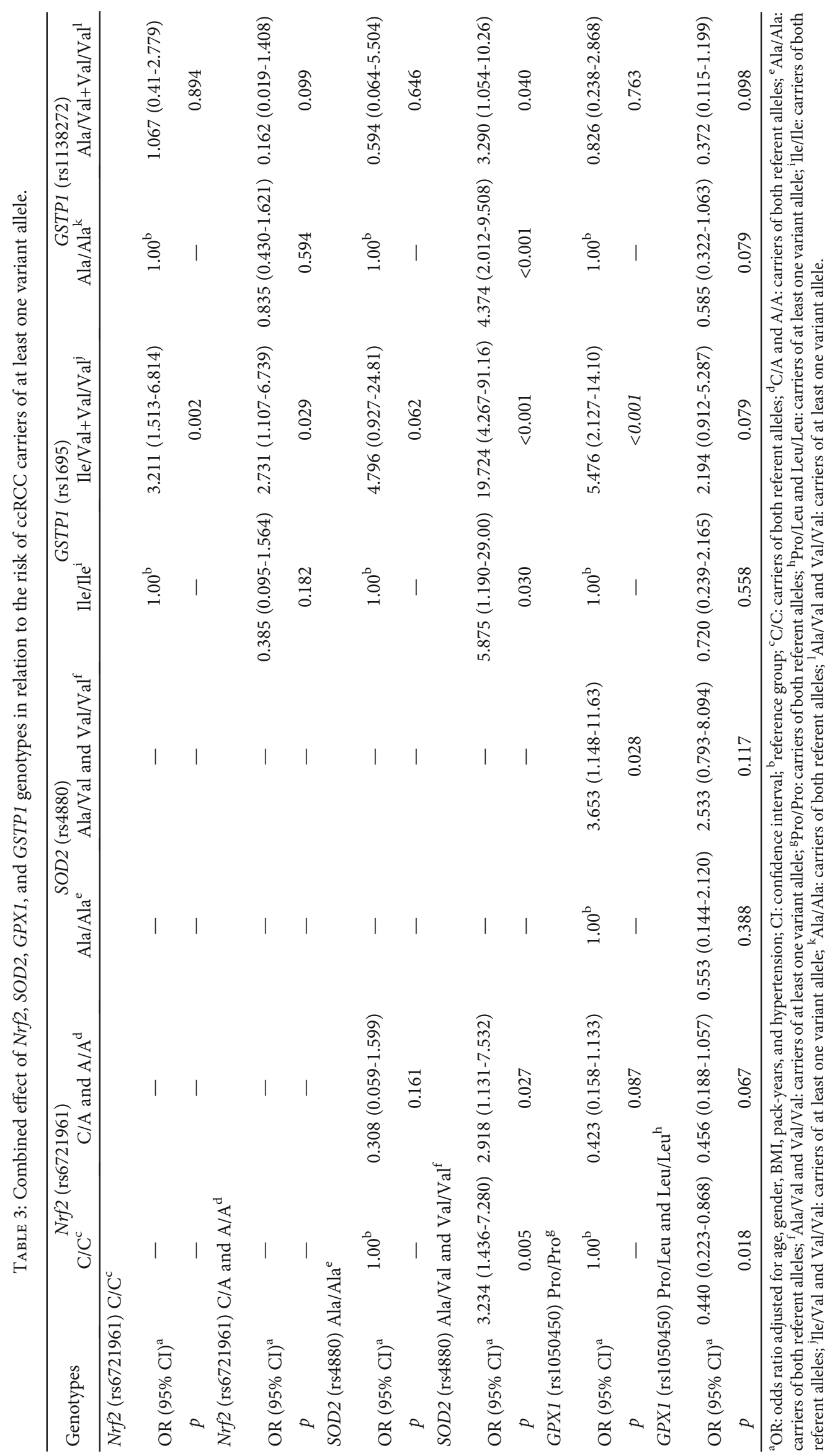


TABLE 4: Haplotype analysis of GSTP1 rs1695 and rs1138272 polymorphisms in patients with ccRCC.

\begin{tabular}{|c|c|c|c|c|c|c|}
\hline & \multirow{2}{*}{$\begin{array}{c}\text { Genotype } \\
\text { rs1695 }\end{array}$} & \multicolumn{4}{|c|}{ Haplotype frequencies } & \multirow[b]{2}{*}{$p$ value } \\
\hline & & rs1138272 & ccRCC patients, $\%$ & Controls, \% & OR $(95 \% \mathrm{CI})^{\mathrm{a}}$ & \\
\hline GSTP1A ${ }^{\mathrm{d}}$ & $* \mathrm{~A}$ & $* \mathrm{C}$ & 56 & 64 & $1.00^{\mathrm{b}}$ & \\
\hline$G S T P 1 B^{\mathrm{e}}$ & $* \mathrm{G}$ & $* \mathrm{C}$ & 38 & 30 & $1.50(1.10-2.05)$ & 0.012 \\
\hline GSTP1C & $* \mathrm{G}$ & $* \mathrm{~T}$ & 5 & 3 & $3.50(1.49-8.22)$ & 0.004 \\
\hline \multirow[t]{2}{*}{$G S T P 1 D^{\mathrm{g}}$} & $* \mathrm{~A}$ & $* \mathrm{~T}$ & 1 & 3 & $0.00\left(\mathrm{~N} / \mathrm{A}^{\mathrm{c}}\right)$ & 1.000 \\
\hline & \multicolumn{6}{|c|}{ Global haplotype association $p$ value: $<0.001$} \\
\hline
\end{tabular}

${ }^{\mathrm{a}}$ OR: odds ratio adjusted for age, gender, BMI, pack-years, and hypertension; CI: confidence interval; ${ }^{\mathrm{b}}$ reference group; ${ }^{\mathrm{c}} \mathrm{N} / \mathrm{A}$ : not applicable; ${ }^{\mathrm{d}}$ GSTP1A genotype consisting of Ile105 and Ala114; ${ }^{\mathrm{e}}$ GSTP1B genotype consisting of Val105 and Ala114; ${ }^{\mathrm{f}}$ GSTP1C genotype consisting of Val105 and Val114; ${ }^{\mathrm{g}}$ GSTP1D genotype consisting of Ile105 and Val114.

TABLE 5: Nrf2, SOD2, GPX1, and GSTP1 genotype distribution among living and deceased ccRCC patients.

\begin{tabular}{|c|c|c|c|}
\hline Genotype & Living patients, $n(\%)$ & Deceased patients, $n(\%)$ & $p$ value \\
\hline \multicolumn{4}{|l|}{ Nrf2 (rs6721961) } \\
\hline $\mathrm{C} / \mathrm{C}^{\mathrm{a}}$ & $99(76)$ & $59(75)$ & \\
\hline $\mathrm{C} / \mathrm{A}$ and $\mathrm{A} / \mathrm{A}^{\mathrm{b}}$ & $31(24)$ & $19(25)$ & 0.530 \\
\hline \multicolumn{4}{|l|}{ SOD2 (rs4880) } \\
\hline $\mathrm{Ala} / \mathrm{Ala}^{\mathrm{c}}$ & $31(24)$ & $12(15)$ & \\
\hline Ala/Val and $\mathrm{Val} / \mathrm{Val}^{\mathrm{d}}$ & $101(76)$ & $68(85)$ & 0.093 \\
\hline \multicolumn{4}{|l|}{ GPX1 (rs1050450) } \\
\hline Pro/Pro ${ }^{\mathrm{e}}$ & $57(43)$ & $46(57)$ & \\
\hline Pro/Leu and Leu/Leu ${ }^{\mathrm{f}}$ & $77(57)$ & $34(43)$ & 0.024 \\
\hline \multicolumn{4}{|l|}{ GSTP1 (rs1695 and rs1138272) } \\
\hline$($ Ile/Ile $)(\text { Ala/Ala })^{g}$ & $41(31)$ & $12(15)$ & \\
\hline $\begin{array}{l}(\mathrm{Ala} / \mathrm{Ala})(\mathrm{Pro} / \mathrm{Leu}+\mathrm{Leu} / \mathrm{Leu}) \\
(\mathrm{Ala} / \mathrm{Val}+\mathrm{Val} / \mathrm{Val})(\text { Pro/Pro }) \\
(\mathrm{Ala} / \mathrm{Val}+\mathrm{Val} / \mathrm{Val})(\text { Pro/Leu+Leu/Leu })^{\mathrm{h}}\end{array}$ & $93(69)$ & $68(85)$ & 0.007 \\
\hline
\end{tabular}

${ }^{\mathrm{a}} \mathrm{C} / \mathrm{C}$ : carriers of both referent alleles; ${ }^{\mathrm{b}} \mathrm{C} / \mathrm{A}$ and $\mathrm{A} / \mathrm{A}$ : carriers of at least one variant allele; ${ }^{\mathrm{c} A l a / A l a: ~ c a r r i e r s ~ o f ~ b o t h ~ r e f e r e n t ~ a l l e l e s ; ~}{ }^{\mathrm{d}} \mathrm{Ala} / \mathrm{Val}$ and $\mathrm{Val} / \mathrm{Val}$ : carriers of at least one variant allele; ${ }^{\mathrm{e}}$ Pro/Pro: carriers of both referent alleles; ${ }^{\mathrm{f}}$ Pro/Leu and Leu/Leu: carriers of at least one variant allele; ${ }^{\mathrm{g}}$ (Ile/Ile) (Ala/Ala): carriers of both referent alleles for rs1695 and rs1138272; ${ }^{\mathrm{h}}$ carriers of at least one variant allele for either rs1695 or rs1138272.

$\mathrm{CI}=1.148-11.630, \quad p=0.028$ and $\mathrm{OR}=5.476,95 \% \mathrm{CI}=$ 2.127-14.102, $p<0.001$, respectively).

In the next step, haplotype analysis of GSTP1 rs1695 and rs 1138272 polymorphisms was performed and is presented in Table 4. The GSTP1A genotype represents a combination of A313 and C114, meaning that the enzyme has isoleucine at position 105 and alanine at 114. The genotype with G313 and C114 or valine at 105 and alanine at 114 is GSTP1B. The presence of G313 and T114 or valine at both 105 and 114 represents GSTP1C, while the form consisting of isoleucine at position 105 and valine at 114 (A313 and T114) is GSTP1D [40]. The haplotype composed of wild-type alleles $* \mathrm{~A}$ and $* \mathrm{C}$ was the most frequent among ccRCC patients (56\%) and controls (64\%). Regarding the effect of the GSTP1ABCD haplotype on ccRCC susceptibility, the haplotype consisting of variant alleles of both polymorphisms $* \mathrm{G}$ and $* \mathrm{~T}$ was associated with 3.5 -fold increased risk $(\mathrm{OR}=3.50,95 \% \mathrm{CI}=1.49-8.22, p=0.004)$.

3.2. Follow-Up Analysis. Of 223 ccRCC cases, follow-up data were acquired for 215 (96\%) patients in a period from 2005 to
2018. There were a total number of 80 deaths (37\%) and 135 survivals during the mean follow-up period of $67.31 \pm 37.68$ months (ranging from 1 to 161 months). Table 5 presents Nrf2, SOD2, GPX1, and GSTP1 genotype distribution among living and deceased ccRCC patients.

Statistically significant difference in frequencies was observed among carriers of Pro/Leu and Leu/Leu genotypes of the examined GPX1 polymorphism $(p=0.024)$. Regarding the GSTP1ABCD haplotype, statistically significant difference in frequencies was observed between carriers of at least one variant allele and carriers of a referent genotype of both GSTP1 polymorphisms (Table 5).

Table 6 represents the analysis of different examined genotypes as potential predictors for overall mortality. The analysis was performed in two models, based on different adjustments. Although without reaching statistical significance, the GSTP1-variant genotype consisting of at least one Val105 allele in the case of rs1695, in combination with at least one Val114 allele in the case of rs1138272, expressed the highest hazard ratio in ccRCC patients (model $1 \mathrm{HR}=$ $1.627,95 \% \mathrm{CI}=0.664-3.986, p=0.287$; model $2 \mathrm{HR}=3.897$, 
TABLE 6: Nrf2, SOD2, GPX1, and GSTP1 polymorphisms as predictors for overall mortality in patients with ccRCC.

\begin{tabular}{|c|c|c|c|}
\hline \multicolumn{2}{|c|}{ Model $1^{\mathrm{a}}$} & \multicolumn{2}{|c|}{ Model $2^{\mathrm{b}}$} \\
\hline HR (95\% CI) & $p$ value & HR (95\% CI) & $p$ value \\
\hline \multicolumn{4}{|c|}{ Risk for overall mortality comparing Nrf2-variant ${ }^{\mathrm{c}}$ genotype to Nrf2-reference ${ }^{\mathrm{d}}$-type genotype carriers } \\
\hline $1.030(0.579-1.833)$ & 0.919 & $1.104(0.456-2.674)$ & 0.826 \\
\hline \multicolumn{4}{|c|}{ Risk for overall mortality comparing SOD2-variant ${ }^{\mathrm{e}}$ genotype to SOD2-reference $\mathrm{f}^{\mathrm{f}}$-type genotype carriers } \\
\hline $1.290(0.676-2.461)$ & 0.440 & $1.687(0.494-5.755)$ & 0.404 \\
\hline \multicolumn{4}{|c|}{ Risk for overall mortality comparing GPX1-variant ${ }^{\mathrm{g}}$ genotype to GPX1-reference ${ }^{\mathrm{h}}$-type genotype carriers } \\
\hline $0.737(0.462-1.177)$ & 0.201 & $1.388(0.654-2.946)$ & 0.393 \\
\hline \multicolumn{4}{|c|}{ Risk for overall mortality comparing GSTP1-variant ${ }^{\mathrm{i}}$ genotype to GSTP1-reference ${ }^{\mathrm{j}}$-type genotype carriers } \\
\hline $1.627(0.664-3.986)$ & 0.287 & $3.897(0.681-22.304)$ & 0.126 \\
\hline
\end{tabular}

${ }^{a}$ Model 1 adjusted for age and gender; ${ }^{b}$ model 2 adjusted for the covariates from model 1 and recognized risk factors for ccRCC development (pack-years, BMI, and hypertension); ${ }^{\mathrm{c}} \mathrm{Nrf2}$-variant-type genotype-C/A+A/A; ${ }^{\mathrm{d}} \mathrm{Nrf2-reference}$ genotype-C/C; ${ }^{\mathrm{e}} \mathrm{SOD} 2$ variant-type genotype-Ala/Val+Val/Val; ${ }^{\mathrm{f}} \mathrm{SOD} 2$ reference genotype-Ala/Ala; ${ }^{\mathrm{g}}$ GPX1-variant-type genotype-Pro/Leu+Leu/Leu; ${ }^{\mathrm{h}}$ GPX1-reference genotype-Pro/Pro; ${ }^{\mathrm{i}}$ GSTP1-variant-type genotype-combination of genotypes of rs1695 and rs1138272 SNPs (Ile/Val+Val/Val) (Ala/Val+Val/Val); ${ }^{j}$ GSTP1-reference genotype-combination of reference genotypes of both rs1695 and rs1138272 (Ile/Ile) (Ala/Ala); HR: hazard ratio; CI: confidence interval.

$95 \% \mathrm{CI}=0.681-22.304, p=0.126)$. On the other hand, none of the other investigated genotypes showed any predicting potential in terms of ccRCC overall mortality.

The Kaplan-Meier survival curves for overall mortality according to Nrf2, GSTP1, SOD2, and GPX1 genes in ccRCC patients are presented in Figure 1. This analysis for overall survival did not show significantly shorter time of survival in patients carrying a specific Nrf2, SOD2, or GPX1 genotype $(p>0.05$, Figures 1(a), 1(c), and 1(d)). However, patients who were carrying any of variant GSTP1 genotypes were recognized as patients with shorter overall survival (log-rank $p=0.038$ ) (Figure 1(b)).

3.3. Analysis of Protein Expression. Since GSTP1 protein may negatively regulate JNK and therefore affect the apoptotic activity, especially within tumor tissue, we analyzed the GSTP1 protein expression both in a pool of nontumor kidney tissue samples and in ccRCC tissue samples, however independently of the GSTP1 genotype. Moreover, the potential presence of GSTP1 : JNK1/2 complexes was assessed in specimens of tumor tissue obtained from 20 patients with ccRCC. Despite gradual increase in the expression across tumor grades (G1-G3), significant difference was not observed neither for GSTP1 protein levels in ccRCC tissue samples alone (Figure 2, $p>0.05$ ) nor between the nontumor kidney tissue pool and ccRCC tissue samples $(p>0.05)$.

Although the JNK1/2 expressed was evidently higher in the nontumor kidney tissue pool in comparison with ccRCC tissue samples (Figure 3), the obtained results were not statistically significant $(p>0.05)$.

Still, the expression of executor cleaved caspase- 3 gradually decreased across tumor grade (G1-G3), reaching the statistical significance only in G3, when compared to the pool of nontumor kidney tissue samples (Figure $4, p<0.05$ ).

However, a weak positive correlation (correlation coefficient, $r<0.3$ ) was found only between GSTP1 and cleaved caspase-3 expression ( $r=0.024, p=0.999)$.

In order to investigate the presence of GSTP1:JNK1 protein: protein interactions, tumor tissue samples were divided into three groups, according to the tumor's grade. Although the effect of GSTP1 polymorphic expression was not assessed, the analyzed samples comprised all three GSTP genotypes. Namely, the GSTP1 IleIle genotype was present in 30\%, GSTP1 IleVal in 40\%, and GSTP1 ValVal in 30\% samples. Protein immunoprecipitation, followed by Western blot analysis, showed the presence of JNK1/2/GSTP1 complexes in all assessed ccRCC samples (Figure 5).

\section{Discussion}

In recent years, attention has been raised toward genetic variants, often referred to as "quantitative trait loci" that could contribute to a small, but significant, risk not only for the development but also for the progression of complex disorder such as cancer [41]. Deleterious effects of SNP polymorphisms found in genes encoding transcriptional factors, as well as antioxidant and detoxification enzymes, are still disputable; however, their functional significance might seem to modify the risk for RCC development. Moreover, there is a growing body of evidence that glutathione transferases may participate in tumor progression and affect patients' survival by regulating a number of cellular processes via protein:protein interactions as endogenous negative regulators of protein kinases [16, 17, 42-45].

In this study, we examined the role of genetic polymorphisms of the transcriptional factor Nrf2 and genes coding SOD2 and GPX1, as well as GSTP1, in ccRCC development. We noticed an increased risk of ccRCC development among carriers of variant genotypes of both SOD2 rs4880 and GSTP1 rs1695 polymorphisms. Nrf2 rs6721961 genetic polymorphism in combination with both rs4880 and rs1695 showed higher risk for this type of tumor as well. Since two examined SNPs of GSTP1, rs1695 and rs1138272, are close in their position, haplotype analysis was performed. It revealed that significant risk of ccRCC development is associated with a genotype consisting of variant forms of both polymorphisms, while the molecular mechanism underlying the role of GSTP1 forms in RCC progression might be explained by the presence of GSTP1:JNK1/2 protein:protein interactions. 


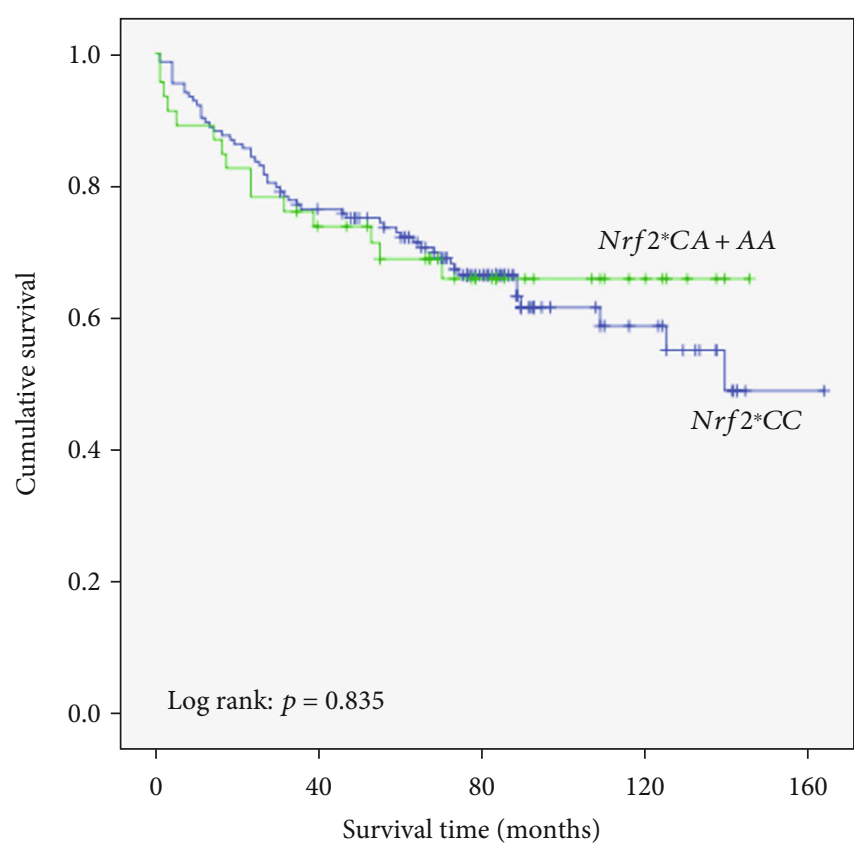

(a)

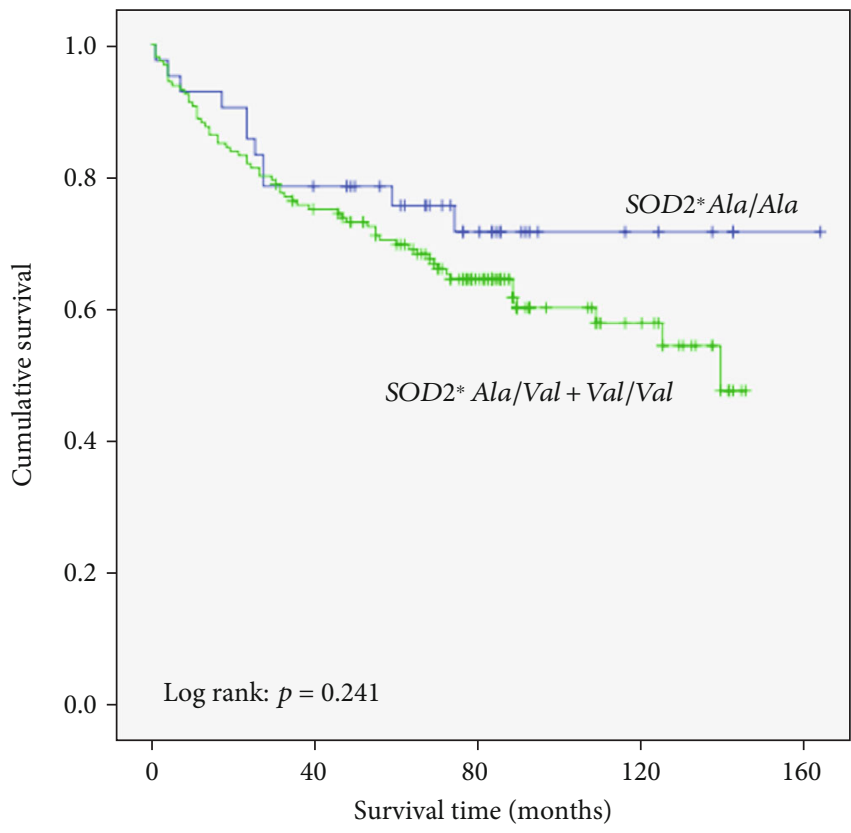

(c)

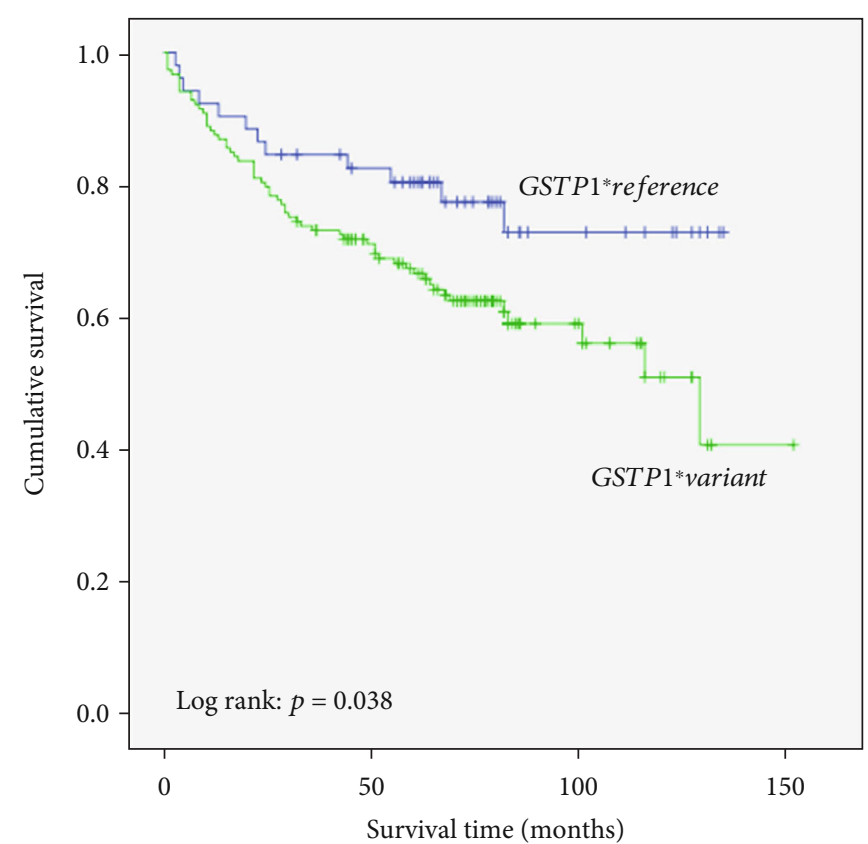

(b)

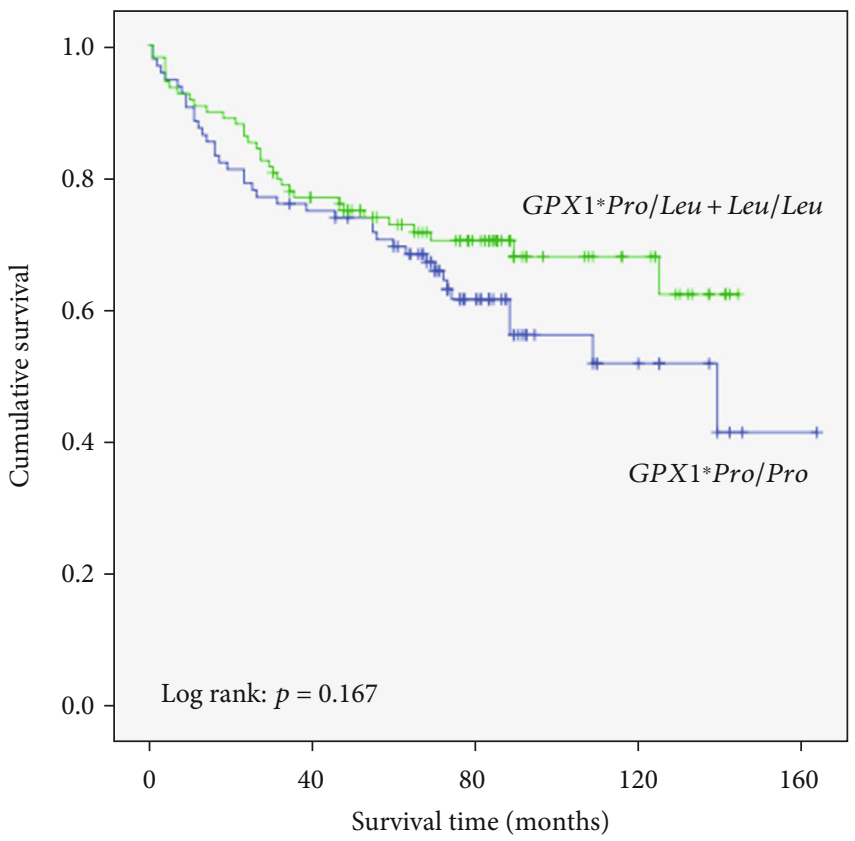

(d)

Figure 1: Kaplan-Meier survival curves for overall mortality according to (a) Nrf2 polymorphism, (b) GSTP1 polymorphisms rs1695 and rs1138272 in combination (GSTP1 * reference genotype-(Ile/Ile) (Ala/Ala); GSTP1 * variant-type genotypes-(Ile/Val+Val/Val)(Ala/Ala), (Ile/Ile)(Ala/Val+Val/Val), and (Ile/Val+Val/Val)(Ala/Val+Val/Val)), (c) SOD2 polymorphism, and (d) GPX1 polymorphism.

It has been shown that Nrf2 deficiency decreases the ability of tissue to properly react to exposure to oxidative and electrophilic stressors [46]. The importance of SNP rs6721961 for further Nrf2 activity has been shown, since this polymorphism is positioned in the middle of the ARE motif and affects the binding of Nrf2 to the ARE. Homozygous $A / A$ subjects exhibit lower level of Nrf2 mRNA which further leads to lower protein activity [47]. Suzuki et al. demonstrated that smokers-carriers of the A/ANrf2 genotype-- had increased risk of lung cancer development [47], while at the same time, Okano et al. even suggested that this polymorphism should be considered a prognostic biomarker for assessing prognosis in lung adenocarcinoma patients [29]. What is more, women carrying this specific genotype have higher risk for breast cancer development and decreased protein expression in cancer tissue [48].

There are no studies of whether the Nrf2-617C/A polymorphism has impact on RCC development. When it comes 

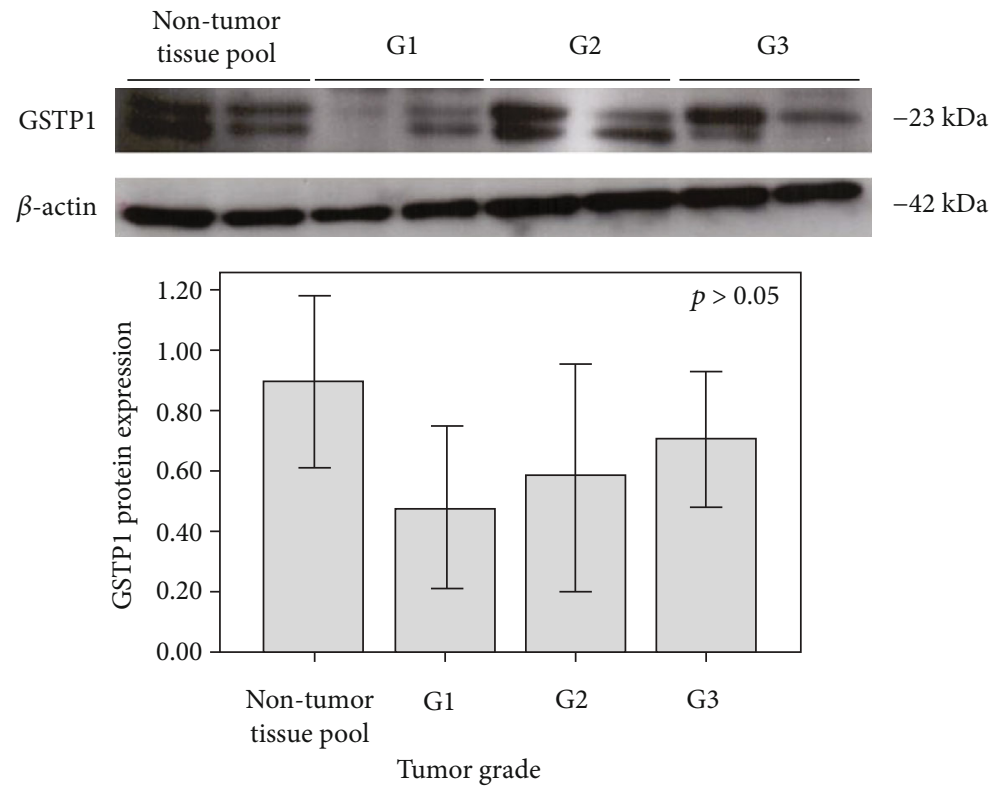

FIgURE 2: Expression of GSTP1 $(23 \mathrm{kDa})$ protein analyzed by immunoblot in a pool of nontumor kidney tissue samples, as well as in ccRCC tissue samples (G1-G3). G1: tumor grade I; G2: tumor grade II; G3: tumor grade III. Expression of $\beta$-actin (42 kDa) protein in a pool of nontumor kidney tissue samples, as well as in ccRCC tissue samples (G1-G3), is used as a normalization control.

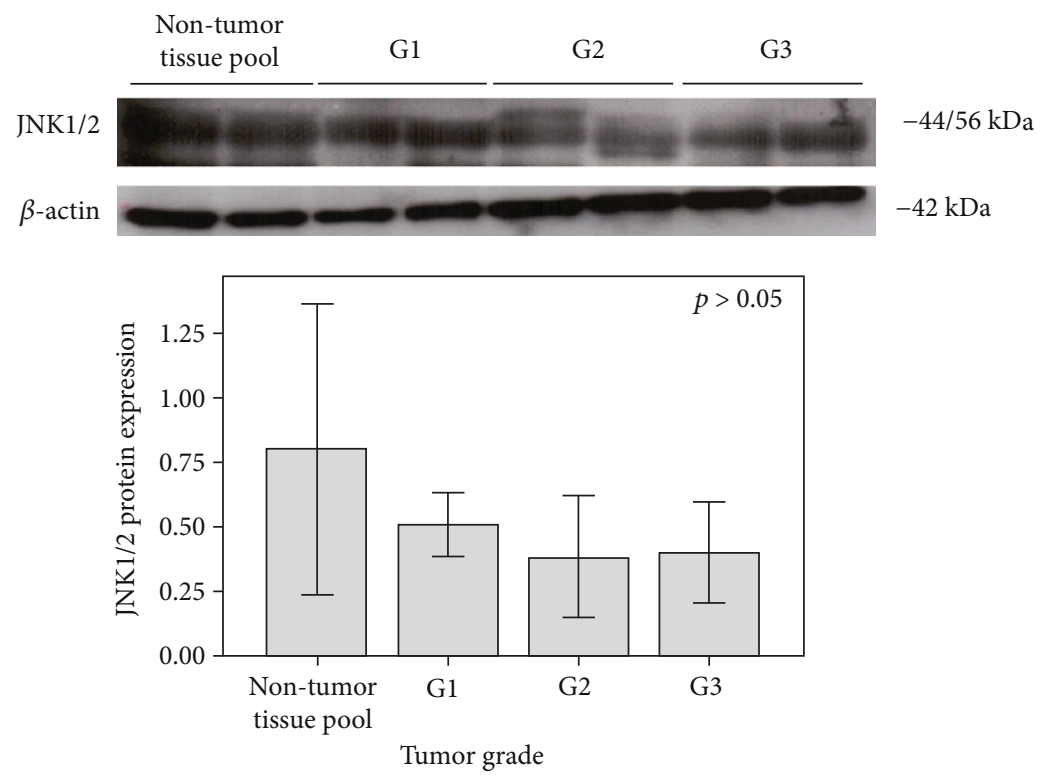

FIGURE 3: Expression of JNK1/2 (44/56 kDa) protein in a pool of nontumor kidney tissue samples, as well as in ccRCC tissue samples (G1-G3). G1: tumor grade I; G2: tumor grade II; G3: tumor grade III. Expression of $\beta$-actin $(42 \mathrm{kDa})$ protein in a pool of nontumor kidney tissue samples, as well as in ccRCC tissue samples (G1-G3), is used as a normalization control.

to tumors of the urinary tract, Reszka et al. found no association between SNP rs6721961 and risk for urinary bladder cancer [27]. Similarly, our results did not show any significant difference in frequencies of different genotypes among ccRCC patients and corresponding controls. Still, in already developed renal cell carcinoma, higher expression of Nrf2 protein in carriers of the $C / C$ genotype seems to point out the patients with poor prognosis and shorter overall survival [49]. Furthermore, when the expression of Nrf2 is elevated, RCC metastasis has inadequate and unsatisfying response to therapy which leads to unfavorable outcome [50]. According to our follow-up analysis, patients with the $C / C$ genotype did have shorter overall survival compared to $C / A$ and $A / A$ carriers, although it was not statistically significant.

Many genes targeted by Nrf2 encode enzymes essential in antioxidative stress response which enables cellular adaptation to new conditions [47]. Glutathione S-transferases as enzymes regulated by $\mathrm{Nrf} 2$ activity take part in defense against stressors [51]. Although meta-analysis did not find association between GSTP1 rs1695 polymorphism and RCC 


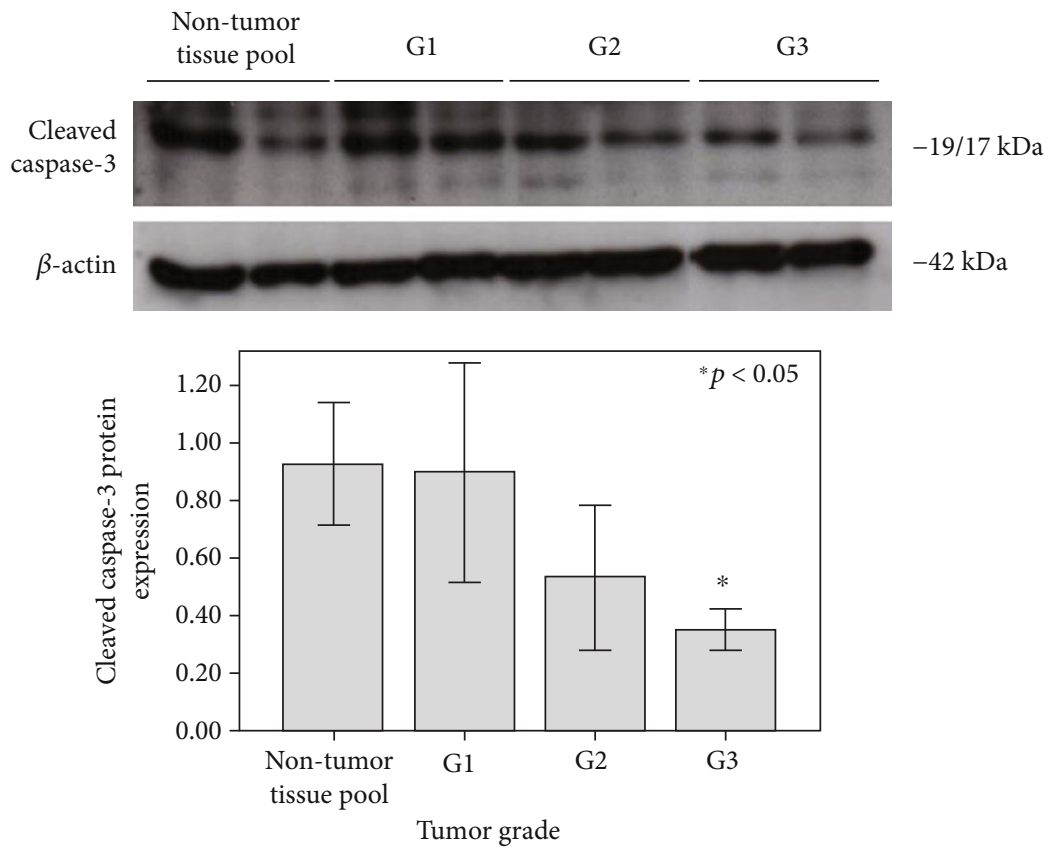

Figure 4: Expression of cleaved caspase-3 $(19 / 17 \mathrm{kDa})$ protein in a pool of nontumor kidney tissue samples, as well as in ccRCC tissue samples $(\mathrm{G} 1-\mathrm{G} 3)\left({ }^{*} p<0.05\right)$. Expression of $\beta$-actin $(42 \mathrm{kDa})$ protein in a pool of nontumor kidney tissue samples, as well as in ccRCC tissue samples (G1-G3), is used as a normalization control.

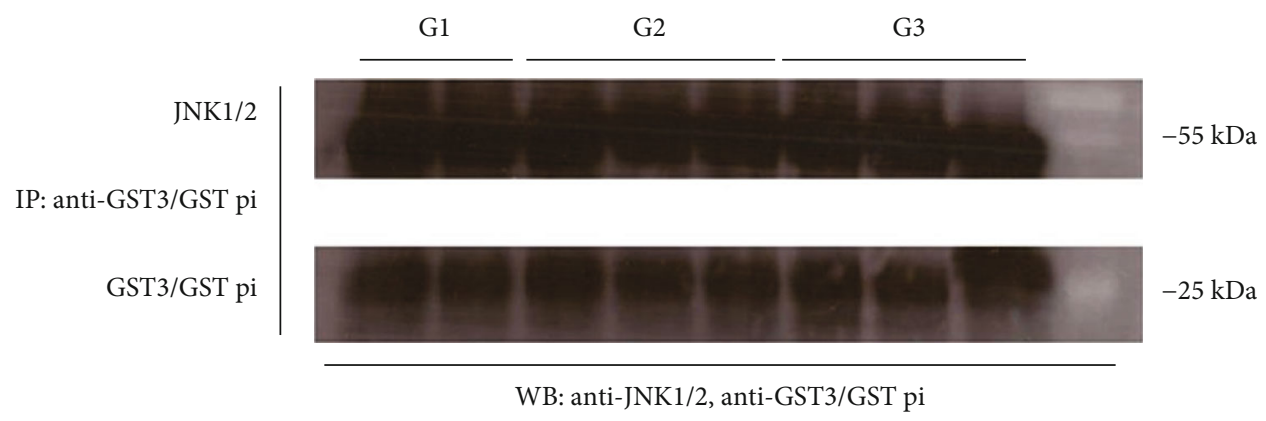

FIGURE 5: Cytosols obtained from ccRCC tissue homogenates were immunoprecipitated with an anti-GST3/GST pi antibody. The samples were subjected to SDS-PAGE on 10\% gel, followed by incubation with the primary antibodies against GST3/GST pi and JNK1/2. G1: tumor grade I; G2: tumor grade II; G3: tumor grade III; IP: immunoprecipitation; WB: Western blot.

development [31, 52], the results of our previous studies on RCC patients indeed demonstrated a significantly increased risk for cancer development in patients carrying the GSTP1-variant (Ile/ $\mathrm{Val}+\mathrm{Val} / \mathrm{Val}$ ) genotype [16], which was in line with the results obtained on the subpopulation of ccRCC patients [53]. In addition to rs1695, in this study, we analyzed rs1138272 SNP as well. There was significant difference in distribution of the rs1695 genotype among patients and controls, but no association between ccRCC and rs1138272. Four haplotypes involving these two polymorphisms have been defined. Maniglia et al. found haplotypes GSTP1A and GSTP1D having higher frequency among cases of head and neck squamous cell carcinoma than among controls [54]. Since the overall functions of GSTs also include the regulation of cell signaling, the GSTP1C haplotype has been considered a better c-Jun N-terminal kinase 1 inhibitor than the reference GSTP1A haplotype [32]. In line with these results, our study showed higher risk for ccRCC for carriers of the GSTP1C haplotype.

Based on the established role of the GSTPi class in inhibition of JNK1 and its antiapoptotic effect [17, 45], we assessed the expression of GSTP1 and expression of regulatory (JNK1/2) and executor (caspase-3) apoptotic molecules in human ccRCC tissue samples, as well as the presence GSTP1:JNK1/2 protein: protein interactions, however irrespective of the GSTP1 genotype. At first, we noticed gradual increase in the GSTP1 protein across tumor grades, although without significant difference. Secondly, our results showed lower level of JNK1/2 expressed in tumor tissue in comparison with nontumor kidney tissue. Furthermore, the expression of cleaved caspase-3, one of the key executory enzymes leading to apoptosis, was statistically significantly decreased in grade 3 when compared to expression in nontumor tissue. In addition, we found a weak, yet positive, correlation 
between GSTP1 and cleaved caspase- 3 expression. Finally, by analyzing ccRCC tissue homogenates, we found GSTP1: JNK1/2 complexes in all assessed samples. The particular interaction has been found in human leukemia, hepatic carcinoma, bladder cancer, and neuroblastoma cells [55]. Presumably, tumors with upregulated GSTP1, such as RCC, could have their kinase-dependent apoptotic signaling pathways suppressed, owning to negative regulation of JNK1. Thévenin et al. showed that protein produced in carriers of the Val105 and Val114 genotype acts as a better JNK inhibitor [32]. Indeed, our results have shown that carriers of GSTP1-variant-type genotypes-(Ile/Val+Val/Val) (Ala/Val $+\mathrm{Val} / \mathrm{Val})$-exhibited poorer survival. It is important to note that the GSTP-JNK interaction is shown to be redoxdependent with possible formation of oligomeric forms of GSTP and other thiol-containing proteins, such as Prdx both 1 and $6[56,57]$. Since Prdx6 seems to be responsible for substantial inhibition of GSTP1 heterodimerization, independently of allelic variations, while Prdx1, once released from the GSTP-JNK complex, maintains its peroxidase activity, it seems plausible that genetic variations in $\operatorname{Prdx}$, both 1 and 6 , might play a critical role in this context [57].

Another enzyme influenced by Nrf2 is manganese superoxide dismutase. Involvement of polymorphism rs4880 in cancer susceptibility has been extensively investigated. Comprehensive meta-analysis by Wang et al. showed SOD2 rs4880 polymorphism to be connected with lung cancer [58]. Various meta-analyses found no association between this SNP and urinary bladder or breast cancer risk [21, 59]. Those studies that actually reported increased risk for breast cancer usually reported the Ala/Ala genotype to be the most frequent, although the carriers of the Val16 variant are expected to be at greater cancer risk [60]. Similarly, some authors found aggressive forms of prostate cancer to be associated with the Ala/Ala genotype [61]. Atilgan et al. found that risk for development of any kind of histologic subtypes of renal cell carcinoma is increased with Ala/Val and Ala/Ala genotypes [35]. In our study, when only clear cell carcinoma was observed, carriers of $\mathrm{Ala} / \mathrm{Val}$ and $\mathrm{Val} / \mathrm{Val}$ genotypes were exposed to significantly greater risk. When analyzed in combination with Nrf2, GPX1, and both rs1695 and rs1138272 GSTP1 SNPs, significant risk was also noted. In addition, according to our results, overall survival was shorter among patients with $\mathrm{Ala} / \mathrm{Val}$ and $\mathrm{Val} / \mathrm{Val}$ genotypes still without statistical significance. It is suggested that the Val16 variant of SOD 2 comprises parts of $\beta$-sheet structure and therefore is inefficiently transported into the mitochondrial cytosol which diminishes its function and further leads to inadequate superoxide anion neutralization [62]. However, Dasgupta et al. found that excessive $\mathrm{H}_{2} \mathrm{O}_{2}$ production leads to reduced sensitivity to tumor necrosis factor- $\alpha$-mediated apoptosis [63]. Hence, it is still debated whether higher or lower SOD2 protein activity should be seen as a definite risk factor.

Glutathione peroxidase- 1 is considered a gatekeeper able to stop detrimental damage caused by $\mathrm{H}_{2} \mathrm{O}_{2}$ produced by higher SOD2 activity [64]. In different stages of carcinogenesis, regulation of GPX1 levels is essential [65]. Many authors advocate SNP rs1050450 in the GPX1 gene to contribute to susceptibility to various cancers $[36,66]$. Namely, metaanalysis investigating the effect of this polymorphism revealed that variant genotypes (Pro/Leu and Leu/Leu) were associated with increased risk for lung cancer, bladder cancer, prostate cancer, head and neck cancer, and brain cancer $[21,67,68]$. However, Nikic et al. found no impact of GPX1 polymorphism on overall survival in patients with metastatic urothelial bladder cancer [69]. Our results did not reveal increased risk for carriers of Pro/Leu and Leu/Leu; on the contrary, risk was reduced among these subjects. Follow-up analysis revealed that these variant allele carriers had shorter cumulative survival, but this was not statistically significant. This is not the first time to encounter that the Leu allele is associated with protection. Considering the fact that the variant GPX1 exhibits lower enzyme activity, the explanation of such phenomenon in ccRCC is challenging. However, as recently suggested, the roles of hydrogen peroxide in signal transduction and regulation of genes involved in longevity might have priority when compared to its potential to cause oxidative damage [70]. Further studies are needed to elucidate the mechanisms by which alteration in $\mathrm{H}_{2} \mathrm{O}_{2}$ reduction is associated with better survival and lower susceptibility to clear cell renal cell carcinoma.

Just recently, when expression of GPX1 protein was evaluated in RCC, high GPX1 level was in a positive correlation with tumor stage, distant metastasis, lymphatic metastasis, and shorter overall survival [24]. These contradictory results on the influence of GPX1 polymorphism on both enzyme synthesis and activity should be further examined and revealed.

This study has several limitations that need to be addressed. The case-control study design and therefore selection bias, as well as the recall bias, regarding the recognized risk factors for ccRCC development might have influenced the results. Also, the control group was relatively small and comprised of hospital-based patients. Furthermore, the possible effect of ethnicity could not be evaluated as the study group consisted of Caucasians only.

\section{Conclusions}

Some important novel aspects regarding the role of SNPs in genes encoding the transcriptional factor Nrf2, mitochondrial SOD2, and GPX1 and GSTP1ABCD haplotype in pathophysiology of ccRCC are provided in this study. Namely, increased ccRCC susceptibility was observed among carriers of individual variant genotypes of both SOD2 rs4880 and GSTP1 rs1695 polymorphisms, as well as in combination with Nrf2 rs6721961 genetic polymorphism. Furthermore, GSTP1ABCD haplotype analysis revealed significant risk of ccRCC development in carriers of the GSTP1C haplotype consisting of variant forms of both GSTP1 polymorphisms comprising this haplotype. Our study also provides evidence in favor of hypothesis that certain GST variant genotypes represent not only significant genetic risk factors for ccRCC development but also a significant prognostic factor. In this line, GSTP1 variant forms seem to affect the overall survival in patients with ccRCC and the proposed molecular mechanism underlying the role of GSTP1 forms in RCC progression 
might be the presence of GSTP1:JNK1/2 protein:protein interactions.

\section{Data Availability}

The data that support the findings of this study are available from the corresponding author (MPE) upon reasonable request.

\section{Disclosure}

A portion of the results presented in this paper (Western blot analysis) is a part of the $\mathrm{PhD}$ thesis from Vesna Coric, MD, conducted and defended at the Faculty of Medicine, University of Belgrade.

\section{Conflicts of Interest}

The authors declare that there is no conflict of interest regarding the publication of this paper.

\section{Acknowledgments}

We thank the patients for taking part in the study and clinical staff for facilitating the collections of the samples. This research was funded by the Ministry of Education, Science and Technological Development of Serbia (grant number 175052).

\section{References}

[1] F. Ursini, M. Maiorino, and H. J. Forman, "Redox homeostasis: the golden mean of healthy living," Redox Biology, vol. 8, pp. 205-215, 2016.

[2] S. Mena, A. Ortega, and J. M. Estrela, "Oxidative stress in environmental-induced carcinogenesis," Mutation Research/Genetic Toxicology and Environmental Mutagenesis, vol. 674, no. 1-2, pp. 36-44, 2009

[3] M. Pljesa-Ercegovac, A. Savic-Radojevic, V. Coric, T. Radic, and T. Simic, "Glutathione transferase genotypes may serve as determinants of risk and prognosis in renal cell carcinoma," BioFactors, vol. 46, no. 2, pp. 229-238, 2020.

[4] B. Ljungberg, L. Albiges, Y. Abu-Ghanem et al., "European Association of Urology guidelines on renal cell carcinoma: the 2019 update," European Urology, vol. 75, no. 5, pp. 799810, 2019.

[5] C. Protzel, M. Maruschke, and O. W. Hakenberg, "Epidemiology, aetiology, and pathogenesis of renal cell carcinoma," European Urology Supplements, vol. 11, no. 3, pp. 52-59, 2012.

[6] F. Chen, Y. Zhang, Y. Şenbabaoğlu et al., "Multilevel genomics-based taxonomy of renal cell carcinoma," Cell Reports, vol. 14, no. 10, pp. 2476-2489, 2016.

[7] N. Pandey, V. Lanke, and P. K. Vinod, "Network-based metabolic characterization of renal cell carcinoma," Scientific Reports, vol. 10, no. 1, p. 5955, 2020.

[8] F. P. Fabrizio, M. Costantini, M. Copetti et al., "Keap1/Nrf2 pathway in kidney cancer: frequent methylation of Keap1 gene promoter in clear renal cell carcinoma," Oncotarget, vol. 8, pp. 11187-11198, 2016.
[9] P. Basak, P. Sadhukhan, P. Sarkar, and P. C. Sil, "Perspectives of the Nrf-2 signaling pathway in cancer progression and therapy," Toxicology Reports, vol. 4, pp. 306-318, 2017.

[10] D. V. Chartoumpekis, N. Wakabayashi, and T. W. Kensler, "Keap1/Nrf2 pathway in the frontiers of cancer and noncancer cell metabolism," Biochemical Society Transactions, vol. 43, no. 4, pp. 639-644, 2015.

[11] V. Krajka-Kuźniak, J. Paluszczak, and W. Baer-Dubowska, "The Nrf2-ARE signaling pathway: an update on its regulation and possible role in cancer prevention and treatment," Pharmacology Reports, vol. 69, no. 3, pp. 393-402, 2017.

[12] M. B. Sporn and K. T. Liby, "NRF2 and cancer: the good, the bad and the importance of context," Nature Reviews. Cancer, vol. 12, no. 8, pp. 564-571, 2012.

[13] H. Y. Cho, J. Marzec, and S. R. Kleeberger, "Functional polymorphisms in Nrf2: implications for human disease," Free Radical Biology \& Medicine, vol. 88, no. Part B, pp. 362-372, 2015.

[14] D. Bartolini and F. Galli, "The functional interactome of GSTP: a regulatory biomolecular network at the interface with the Nrf2 adaption response to oxidative stress," Journal of Chromatography, B: Analytical Technologies in the Biomedical and Life Sciences, vol. 1019, pp. 29-44, 2016.

[15] O. Vasieva, "The many faces of glutathione transferase pi," Current Molecular Medicine, vol. 11, no. 2, pp. 129-139, 2011.

[16] V. M. Coric, T. P. Simic, T. D. Pekmezovic et al., "GSTM1 genotype is an independent prognostic factor in clear cell renal cell carcinoma," Urologic Oncology: Seminars and Original Investigations, vol. 35, pp. 409-417, 2017.

[17] P. G. Board and D. Menon, "Glutathione transferases, regulators of cellular metabolism and physiology," Biochimica et Biophysica Acta (BBA) - General Subjects, vol. 1830, no. 5, pp. 3267-3288, 2013.

[18] D. Bartolini, J. Commodi, M. Piroddi et al., "Glutathione Stransferase pi expression regulates the Nrf2-dependent response to hormetic diselenides," Free Radical Biology \& Medicine, vol. 88, no. Part B, pp. 466-480, 2015.

[19] M. Pljesa-Ercegovac, A. Savic-Radojevic, M. Matic et al., "Glutathione transferases: potential targets to overcome chemoresistance in solid tumors," International Journal of Molecular Sciences, vol. 19, no. 12, p. 3785, 2018.

[20] P. C. Hart, M. Mao, A. L. P. de Abreu et al., "MnSOD upregulation sustains the Warburg effect via mitochondrial ROS and AMPK-dependent signalling in cancer," Nature Communications, vol. 6, no. 1, 2015.

[21] M. Cao, X. Mu, C. Jiang, G. Yang, H. Chen, and W. Xue, "Single-nucleotide polymorphisms of GPX1 and MnSOD and susceptibility to bladder cancer: a systematic review and metaanalysis," Tumor Biology, vol. 35, no. 1, pp. 759-764, 2014.

[22] Y. Wang, R. Branicky, A. Noë, and S. Hekimi, "Superoxide dismutases: dual roles in controlling ROS damage and regulating ROS signaling," The Journal of Cell Biology, vol. 217, no. 6, pp. 1915-1928, 2018.

[23] H. Miess, B. Dankworth, A. M. Gouw et al., "The glutathione redox system is essential to prevent ferroptosis caused by impaired lipid metabolism in clear cell renal cell carcinoma," Oncogene, vol. 37, no. 40, pp. 5435-5450, 2018.

[24] Y. Cheng, T. Xu, S. Li, and H. Ruan, "GPX1, a biomarker for the diagnosis and prognosis of kidney cancer, promotes the progression of kidney cancer," Aging (Albany NY), vol. 11, no. 24, pp. 12165-12176, 2019. 
[25] E. Lubos, J. Loscalzo, and D. E. Handy, "Glutathione peroxidase-1 in health and disease: from molecular mechanisms to therapeutic opportunities," Antioxidants \& Redox Signaling, vol. 15, no. 7, pp. 1957-1997, 2011.

[26] J. M. Marzec, J. D. Christie, S. P. Reddy et al., "Functional polymorphisms in the transcription factor NRF2 in humans increase the risk of acute lung injury," The FASEB Journal, vol. 21, no. 9, pp. 2237-2246, 2007.

[27] E. Reszka, Z. Jablonowski, E. Wieczorek et al., "Polymorphisms of NRF2 and NRF2 target genes in urinary bladder cancer patients," Journal of Cancer Research and Clinical Oncology, vol. 140, no. 10, pp. 1723-1731, 2014.

[28] T. Ishikawa, "Genetic polymorphism in the NRF2 gene as a prognosis marker for cancer chemotherapy," Frontiers in Genetics, vol. 5, 2014.

[29] Y. Okano, U. Nezu, Y. Enokida et al., "SNP (-617C>A) in ARE-like loci of the NRF2 gene: a new biomarker for prognosis of lung adenocarcinoma in Japanese non-smoking women," PLoS One, vol. 8, no. 9, article e73794, 2013.

[30] F. Ding, J. P. Li, Y. Zhang, G. H. Qi, Z. C. Song, and Y. H. Yu, "Comprehensive analysis of the association between the Rs1138272 polymorphism of the GSTP1 gene and cancer susceptibility," Frontiers in Physiology, vol. 9, 2019.

[31] X. Yang, S. Long, J. Deng, T. Deng, Z. Gong, and P. Hao, “Glutathione S-transferase polymorphisms (GSTM1, GSTT1 and GSTP1) and their susceptibility to renal cell carcinoma: an evidence-based meta-analysis," PLoS One, vol. 8, no. 5, article e63827, 2013.

[32] A. F. Thévenin, C. L. Zony, B. J. Bahnson, and R. F. Colman, "GST pi modulates JNK activity through a direct interaction with JNK substrate, ATF2," Protein Science, vol. 20, no. 5, pp. 834-848, 2011.

[33] A. M. Moyer, O. E. Salavaggione, T.-Y. Wu et al., "Glutathione Stransferase P1: gene sequence variation and functional genomic studies," Cancer Research, vol. 68, no. 12, pp. 4791-4801, 2008.

[34] D. Li, C. Dandara, and M. I. Parker, "The 341C/T polymorphism in the GSTP1 gene is associated with increased risk of oesophageal cancer," BMC Genetics, vol. 11, no. 1, p. 47, 2010.

[35] D. Atilgan, B. S. Parlaktas, N. Uluocak et al., "The relationship between ALA16VAL single gene polymorphism and renal cell carcinoma," Advances in Urology, vol. 2014, 5 pages, 2014.

[36] D. Ratnasinghe, J. A. Tangrea, M. R. Andersen et al., "Glutathione peroxidase codon 198 polymorphism variant increases lung cancer risk," Cancer Research, vol. 60, no. 22, pp. 63816383, 2000.

[37] Y. Shimoyama, Y. Mitsuda, Y. Tsuruta, N. Hamajima, and T. Niwa, "Polymorphism of Nrf2, an antioxidative gene, is associated with blood pressure and cardiovascular mortality in hemodialysis patients," International Journal of Medical Sciences, vol. 11, no. 7, pp. 726-731, 2014.

[38] H. Towbin, T. Staehelin, and J. Gordon, "Electrophoretic transfer of proteins from polyacrylamide gels to nitrocellulose sheets: procedure and some applications," Proceedings of the National Academy of Sciences of the United States of America, vol. 76, no. 9, pp. 4350-4354, 1979.

[39] U. K. Laemmli, "Cleavage of structural proteins during the assembly of the head of bacteriophage T4," Nature, vol. 227, no. 5259, pp. 680-685, 1970.

[40] I. Žuntar, S. Kalanj-Bognar, E. Topić, R. Petlevski, M. Štefanović, and V. Demarin, "The glutathione Stransferase polymorphisms in a control population and in Alz- heimer's disease patients," Clinical Chemistry and Laboratory Medicine, vol. 42, no. 3, pp. 334-339, 2004.

[41] A. S. Foulkes, Applied Statistical Genetics with R, Springer, New York City, NY, USA, 2008.

[42] E. Laborde, "Glutathione transferases as mediators of signaling pathways involved in cell proliferation and cell death," Cell Death and Differentiation, vol. 17, no. 9, pp. 1373-1380, 2010.

[43] C. C. McIlwain, D. M. Townsend, and K. D. Tew, "Glutathione _S_ -transferase polymorphisms: cancer incidence and therapy," Oncogene, vol. 25, no. 11, pp. 1639-1648, 2006.

[44] J. Pajaud, S. Kumar, C. Rauch, F. Morel, and C. Aninat, "Regulation of signal transduction by glutathione transferases," International Journal of Hepatology, vol. 2012, 11 pages, 2012.

[45] K. D. Tew and D. M. Townsend, "Glutathione-S-transferases as determinants of cell survival and death," Antioxidants \& Redox Signaling, vol. 17, no. 12, pp. 1728-1737, 2012.

[46] T. Ishii, K. Itoh, S. Takahashi et al., "Transcription factor Nrf2 coordinately regulates a group of oxidative stress-inducible genes in macrophages," The Journal of Biological Chemistry, vol. 275, no. 21, pp. 16023-16029, 2000.

[47] T. Suzuki, T. Shibata, K. Takaya et al., "Regulatory nexus of synthesis and degradation deciphers cellular Nrf2 expression levels," Molecular and Cellular Biology, vol. 33, no. 12, pp. 2402-2412, 2013.

[48] J. M. Hartikainen, M. Tengström, V. M. Kosma, V. L. Kinnula, A. Mannermaa, and Y. Soini, "Genetic polymorphisms and protein expression of NRF2 and sulfiredoxin predict survival outcomes in breast cancer," Cancer Research, vol. 72, no. 21, pp. 5537-5546, 2012.

[49] H. Yuki, T. Kamai, S. Murakami et al., "Increased Nrf2 expression by renal cell carcinoma is associated with postoperative chronic kidney disease and an unfavorable prognosis," Oncotarget, vol. 9, no. 47, pp. 28351-28363, 2018.

[50] Y. Yamaguchi, T. Kamai, S. Higashi et al., "Nrf2 gene mutation and single nucleotide polymorphism Rs6721961 of the Nrf2 promoter region in renal cell cancer," BMC Cancer, vol. 19, no. 1, p. 1137, 2019.

[51] S. I. Holley, A. A. Fryer, J. W. Haycock, S. E. W. Grubb, R. C. Strange, and P. R. Hoban, "Differential effects of glutathione S-transferase pi (GSTP1) haplotypes on cell proliferation and apoptosis," Carcinogenesis, vol. 28, no. 11, pp. 2268-2273, 2007.

[52] C. Y. Jia, Y. J. Liu, X. L. Cong et al., "Association of glutathione S-transferase M1, T1, and P1 polymorphisms with renal cell carcinoma: evidence from 11 studies," Tumor Biology, vol. 35, no. 4, pp. 3867-3873, 2014.

[53] V. M. Coric, T. P. Simic, T. D. Pekmezovic et al., "Combined GSTM1-null, GSTT1-active, GSTA1 low-activity and GSTP1-variant genotype is associated with increased risk of clear cell renal cell carcinoma," PLoS One, vol. 11, 2016.

[54] M. P. Maniglia, A. Russo, P. M. Biselli-Chicote et al., "Glutathione S-transferase polymorphisms in head and neck squamous cell carcinoma treated with chemotherapy and/or radiotherapy," Asian Pacific Journal of Cancer Prevention, vol. 21, pp. 1637-1644, 2020.

[55] M. Pljesa-Ercegovac, A. Savic-Radojevic, D. Dragicevic et al., "Enhanced GSTP1 expression in transitional cell carcinoma of urinary bladder is associated with altered apoptotic pathways," Urologic Oncology: Seminars and Original Investigations, vol. 29, no. 1, pp. 70-77, 2011.

[56] K. D. Tew, Y. Manevich, C. Grek, Y. Xiong, J. Uys, and D. M. Townsend, "The role of glutathione S-transferase $\mathrm{P}$ in 
signaling pathways and S-glutathionylation in cancer," Free Radical Biology \& Medicine, vol. 51, no. 2, pp. 299-313, 2011.

[57] Y. Manevich, S. Hutchens, K. D. Tew, and D. M. Townsend, "Allelic variants of glutathione S-transferase P1-1 differentially mediate the peroxidase function of peroxiredoxin VI and alter membrane lipid peroxidation," Free Radical Biology \& Medicine, vol. 54, pp. 62-70, 2013.

[58] J. Wang, Q. Liu, S. Yuan et al., "Genetic predisposition to lung cancer: comprehensive literature integration, meta-analysis, and multiple evidence assessment of candidate-gene association studies," Scientific Reports, vol. 7, no. 1, p. 8371, 2017.

[59] X. Ma, C. Chen, H. Xiong et al., "No association between SOD2 Val16Ala polymorphism and breast cancer susceptibility: a meta-analysis based on 9, 710 cases and 11, 041 controls," Breast Cancer Research and Treatment, vol. 122, no. 2, pp. 509-514, 2010.

[60] A. Crawford, R. G. Fassett, D. P. Geraghty et al., "Relationships between single nucleotide polymorphisms of antioxidant enzymes and disease," Gene, vol. 501, no. 2, pp. 89-103, 2012.

[61] B. Mikhak, D. J. Hunter, D. Spiegelman et al., "Manganese superoxide dismutase (MnSOD) gene polymorphism, interactions with carotenoid levels and prostate cancer risk," Carcinogenesis, vol. 29, no. 12, pp. 2335-2340, 2008.

[62] A. Sutton, A. Imbert, A. Igoudjil et al., "The manganese superoxide dismutase Ala16Val dimorphism modulates both mitochondrial import and MRNA stability," Pharmacogenetics and Genomics, vol. 15, no. 5, pp. 311-319, 2005.

[63] J. Dasgupta, S. Subbaram, K. M. Connor et al., "Manganese superoxide dismutase protects from TNF- $\alpha$-induced apoptosis by increasing the steady-state production of $\mathrm{H} 2 \mathrm{O} 2$," Antioxidants \& Redox Signaling, vol. 8, no. 7-8, pp. 1295-1305, 2006.

[64] D. N. Ekoue, C. He, A. M. Diamond, and M. G. Bonini, "Manganese superoxide dismutase and glutathione peroxidase-1 contribute to the rise and fall of mitochondrial reactive oxygen species which drive oncogenesis," Biochimica et Biophysica Acta (BBA) - Bioenergetics, vol. 1858, no. 8, pp. 628-632, 2017.

[65] R. Brigelius-Flohé and A. Kipp, "Glutathione peroxidases in different stages of carcinogenesis," Biochimica et Biophysica Acta (BBA) - General Subjects, vol. 1790, no. 11, pp. 1555-1568, 2009.

[66] Y. J. Hu and A. M. Diamond, "Role of glutathione peroxidase 1 in breast cancer: loss of heterozygosity and allelic differences in the response to selenium," Cancer Research, vol. 63, no. 12, pp. 3347-3351, 2003.

[67] J. Chen, Q. Cao, C. Qin et al., "GPx-1 polymorphism (Rs1050450) contributes to tumor susceptibility: evidence from meta-analysis," Journal of Cancer Research and Clinical Oncology, vol. 137, no. 10, pp. 1553-1561, 2011.

[68] C. Wang, R. Zhang, N. Chen et al., "Association between glutathione peroxidase-1 (GPX1) Rs1050450 polymorphisms and cancer risk," International Journal of Clinical and Experimental Pathology, vol. 10, no. 9, pp. 9527-9540, 2017.

[69] P. Nikic, D. Dragicevic, A. Savic-Radojevic et al., "Association between GPX1 and SOD2 genetic polymorphisms and overall survival in patients with metastatic urothelial bladder cancer: a single-center study in Serbia," Journal of B.U.ON., vol. 23, no. 4, pp. 1130-1135, 2018.

[70] B. Dragicevic, S. Suvakov, D. Jerotic et al., "Association of SOD2 (Rs4880) and GPX1 (Rs1050450) gene polymorphisms with risk of Balkan endemic nephropathy and its related tumors," Medicina, vol. 55, no. 8, p. 435, 2019. 